\title{
Disaggregate productivity comparisons: sectoral convergence in OECD countries
}

\author{
Johannes Van Biesebroeck
}

(C) Springer Science+Business Media, LLC 2009

\begin{abstract}
International comparisons of productivity have used exchange rates or purchasing power parity (PPP) to make output comparable across countries. While aggregate PPP holds well in the long run, sectoral deviations are persistent. It raises the need for a currency conversion factor at the same level of aggregation as the output that is compared. Mapping prices from household expenditure surveys into the industrial classification of sectors and adjusting for taxes and international trade, I obtain an expenditure-based sector-specific PPP. Using detailed price data for up to 8 years between 1970 and 1999, I test whether the sectoral PPPs adequately capture differential changes in relative prices between countries. They work well for agriculture and the majority of industrial sectors, but not for most service sectors and for manufacturing sectors that produce differentiated products. Using the most appropriate conversion factor for each industry, productivity convergence is found to be taking place in all but a few industries for a group of $14 \mathrm{OECD}$ countries. The latter results are robust to the base year used for the currency conversion.
\end{abstract}

Keywords PPP - Productivity - Convergence . Sectoral comparison $\cdot$ Base year

J. Van Biesebroeck ( $\square$ )

Centre for Economic Studies, K.U. Leuven, Naamsestraat 69, 3000 Leuven, Belgium

e-mail: johannes.vanbiesebroeck@econ.kuleuven.be

J. Van Biesebroeck

University of Toronto, Toronto, ON, Canada

J. Van Biesebroeck

NBER, Cambridge, MA, USA
JEL Classification $\quad$ D24 $\cdot$ F14 $\cdot$ F31 $\cdot$ O47

\section{Introduction}

To compare economy-wide productivity or GDP per capita, researchers usually rely on purchasing power parity (PPP) to convert each country's output into a common currency. A similar conversion at the sectoral level will only capture the productivity difference if the two countries share the same relative prices. Moreover, performing such sectoral comparisons at multiple points in time-for example to study cross-country convergence-will lump price changes with productivity changes if relative prices evolve differently by country.

PPP is constructed by aggregating the relative prices on a basket of identical goods using expenditure weights. This generates an appropriate conversion factor only for output that is well represented by the basket. This is well known. For example, a capital goods PPP is used to convert the value of capital into a common currency as needed to construct comparable TFP levels for different countries.

To compare productivity between countries at the sectoral level, one should exert similar caution. For example, if the price of textiles relative to machinery increases faster in Japan than in the United States, it will not be correct to use the same aggregate PPP to convert both Japanese textile and machinery output into U.S. dollar. Japanese relative productivity growth in textiles will be overestimated and vice versa for machinery.

In the past, Dollar and Wolff (1988) and Bernard and Jones (1996) have used aggregate PPP to convert sectoral output. Sørensen (2001) shows this to be appropriate for the total business or service sectors, but not for manufacturing. 
In response to the Comment by Sørensen (2001), Bernard and Jones (2001) write:

"The clear implication of the Comment is that future research is needed to construct conversion factors appropriate to each sector and that research relying on international comparisons of sectoral productivity should proceed with caution until these conversion factors are available." (p. 1169).

Some recent papers, e.g., Arcelus and Arocena (2000) and Funk and Strauss (2003), still use aggregate PPP for sectoral comparisons. They do not justify their choice, apparently in a belief that it is of secondary importance. ${ }^{1}$

The evidence in Engel and Rogers $(1996,2004)$ highlights that price differences for identical goods are not merely a possibility, but an important phenomenon. Price differences between U.S. and Canadian cities are shown to be much larger than between equidistant cities within the same country. In Europe, price differences between cities are non-negligible either, even though price dispersion reduced significantly over the 1990s. Such a trend implies different evolutions of relative prices across countries and ignoring them will bias sectoral productivity comparisons.

Some studies have recognized the problem and constructed disaggregate conversion factors. Hooper and Larin (1989), Hooper (1996) and Harrigan (1999) use published PPPs for different component factors of GDP. Only a few components are available and the correspondence to industrial sectors is only approximate. Jorgenson et al. (1987) and Pilat (1996) use the more disaggregate underlying data from the same consumer price and expenditure surveys. They map individual product categories-called basic headings-into the sectors for which they observe output. In contrast, van Ark and Pilat (1993) rely on producer price surveys to construct unit value ratios, an alternative to sectoral PPP. In theory, these are superior, but because they cover less products they might perform worse in practice. As these studies only calculate the sectoral PPPs for a single year, they cannot test their validity.

The contribution of this paper is to calculate expenditure-based sectoral PPPs in four different years. ${ }^{2}$ This allows me to verify whether these conversion factors accurately capture changes in relative prices, which is

\footnotetext{
${ }^{1}$ Other recent studies do check the robustness of their findings using a different base year Wong (2006) or unit value ratios as conversion factors (Malley et al. 2003).

${ }^{2}$ When there is no risk for confusion, the label "expenditure-based" will be omitted. In Sect. 4.3, results are presented using additional base years: 1970, 1975, 1980, and 1999. As the price data for the earlier years is slightly different and not all adjustments can be performed for these years, I initially focus on the results for the 1985 , 1990, 1993, and 1996 base years.
}

necessary for them to represent relative prices at different times.

The results are mixed. Sectoral PPPs are up to the task only for a limited set of sectors, in particular for agriculture, mining, total manufacturing, and community, social, and personal services. In most disaggregate manufacturing industries they also work well, but not for non-metallic minerals or for machinery and equipment. Because deflation rates-that turn nominal into real growth rates-and PPPs are constructed from different price and expenditure surveys, inconsistencies are introduced in the comparisons over time.

A related paper is Sørensen and Schjerning (2003), which constructs sectoral PPPs for some manufacturing sectors using the component factors of GDP for different base years. They conclude that they do not pass the baseyear invariance test from Sørensen (2001). In addition to constructing the conversion factors at a more disaggregate level (aggregation tends to exacerbate the problems), for more recent years, and for all sectors in the economy, I focus on a different test. Base-year invariance of the convergence estimates is a necessary condition for the conversion factors to be valid, but it is only an indirect check. I verify directly whether changes in sectoral PPP over time correspond well to price changes relative to the U.S. (the reference country for our PPPs).

An important application for sectoral productivity comparisons is in the convergence debate. Within the OECD countries, GDP per capita or aggregate labor productivity was found to be converging over the last 40 years. ${ }^{3}$ We want to study whether this convergence is uniform across all sectors. An alternative explanation would be the declining importance of sectors with large productivity differentials, such as agriculture (Wong 2006). Using for each sector the conversion factor that best captures relative price evolutions, which is not always sectoral PPP, we find that labor productivity convergence is happening in all but a few industries for a group of 14 OECD countries.

The remainder of the paper is organized as follows: Sect. 2 briefly revisits the issues in comparing crosscountry productivity differentials over time. In Sect. 3, I first discuss the literature on sector-specific (currency) conversion factors. Then, I describe the data and the construction of expenditure-based sectoral PPP. The validity of these measures is evaluated directly, in Sect. 4, by comparing relative price changes with changes in sectoral PPP. In Sect. 5, sectoral convergence rates are calculated and Sect. 6 concludes.

\footnotetext{
3 An overview of the debate with recent evidence can be found in a symposium in the July 1996 issue of the Economic Journal and in Durlauf and Quah (1999).
} 


\section{International productivity comparisons}

To compare the productive efficiency of countries one needs to convert output in local currency values into a common unit. If sufficiently detailed information were available, one could simply compare physical quantities produced per unit of input, but in practice more aggregate output concepts in value terms have to be used. The proper conversion factor, for example into U.S. dollar, converts the value of domestic output into the dollar value of a comparable physical quantity in the U.S. Exchange rates are often deemed inappropriate because they are volatile and are only affected by tradables and financial assets. Goods prices, in practice the weighted average for a basket of goods, accomplish this value-quantity transformation at one point in time. Aggregate PPP is designed to accomplish this for the whole of GDP. The labor productivity level of the Japanese economy relative to the U.S. (in U.S. dollar in 1970) is thus calculated as:

level comparison: $\left(\frac{L P^{J}}{L P^{U S}}\right)_{70}^{\$}=\frac{L P_{70}^{J, ¥} / P P P_{70}^{¥ / \$}}{L P_{70}^{U S, \$}}$,

with $P P P^{¥ / \$}=P^{¥} / P^{\$}$, the number of yen needed to purchase the exact same basket of goods in Japan that costs $\$ 1$ in the U.S. $L P$ is value added divided by total employment or another appropriate input measure. It follows that comparing productivity for a single sector requires a sectoral PPP, based only on the prices of the goods produced in that industry.

To compare the evolution of relative productivity levels over time, two calculations are possible. The most straightforward approach is to compare productivity levels in current prices in both years, according to Eq. 1, and measure the change in this ratio. This requires appropriate conversion factors $\left(P P P_{t}^{¥ / \$}\right)$ in both periods. The change in relative productivity level between Japan and the U.S. from 1970 to 2000 is thus

growth comparison 1:

$$
\frac{\text { relative } L P_{00}^{J / U S}}{\text { relative } L P_{70}^{J / U S}} \equiv \frac{\left(\frac{L P^{J}}{L P^{U S}}\right)_{00}^{\$}}{\left(\frac{L P^{J}}{L P^{U S}}\right)_{70}^{\$}}=\frac{\frac{L P_{00}^{J, \Psi} / P P P_{00}^{\Psi / 8}}{L P_{00}^{U S, S}}}{\frac{L P_{70}^{J, \Psi} / P P P_{70}^{\Psi / 8}}{L P_{70}^{U S, S}}} .
$$

Alternatively, one can calculate productivity growth separately for each country and compare the growth rates. No conversion factors for the level comparisons are needed to study the evolution of relative productivity. Instead, country-specific deflation rates $\left(P_{00} / P_{70}\right)$, turn nominal values for 2000 into real, 1970 values, indicated by $L P_{00,70}$. Dividing real productivity growth for Japan and the U.S. also measures their relative performance: growth comparison 2 :

$$
\frac{1+L P G_{70 / 00}^{J}}{1+L P G_{70 / 00}^{U S}} \equiv \frac{\left(\frac{L P_{00,70}}{L P_{70}}\right)^{J, ¥}}{\left(\frac{L P_{00,70}}{L P_{70}}\right)^{U S, \$}}=\frac{\frac{L P_{00}^{J, ¥} /\left(\frac{P_{00}}{P_{70}}\right)^{¥}}{L P_{70}^{I, \Psi}}}{\frac{L P_{00}^{U S, \$} /\left(\frac{P_{00}}{P_{70}}\right)^{8}}{L P_{70}^{P S, 8}}}
$$

while Eq. 3 can be used to compare the evolution of relative productivity, to study convergence across countries it is still necessary to compare the productivity levels in 1 year, which requires a sectoral price level comparison as in Eq. 1 .

Clearly, if the same basket of goods, prices, and expenditure weights are used to construct both the PPPs and deflation rates, (2) and (3) will produce the same result. Rearranging both equations reveals this will be the case if

$\frac{P P P_{00}^{¥ / \$}}{P P P_{70}^{¥ / \$}}=\frac{\left(\frac{P_{00}}{P_{70}}\right)^{¥}}{\left(\frac{P_{00}}{P_{70}}\right)^{\$}}$

The ratio of the currency conversions factors at both points in time has to equal the ratio of price deflation in both countries. If one country experiences more rapid inflation than the other, its currency should depreciate in PPP terms. In theory, $P P P^{¥ / \$}$ is defined as $P^{¥} / P^{\$}$ and (4) should hold. In practice, both sides are calculated from different price surveys and equality is not guaranteed.

As soon as an industry produces more than one product, a price index has to be constructed and Eq. 4 is guaranteed not to hold with equality. For one, the basket of products used to calculate deflation rates is different (and larger) than the basket used for PPP calculations. More fundamentally, price deflators use own country weights; often a Fisher index number that is the geometric mean of indices using expenditure weights in either year. A similar approach for PPP would entail using the geometric mean of a price index using own and reference country weights, all for the same year. It is well known that extrapolating a country's PPP using its price evolution relative to the benchmark country will miss its next period PPP, which also depends on expenditure shares in other countries Rao (2001). Alternatively, one could just use own country weights to construct PPP, but this is unappealing for multilateral comparisons.

The problem for the convergence analysis is that relative productivity growth is usually calculated using price deflators, according to Eq. 3, because sectoral PPP is considered less reliable or not available in many years. If relative prices evolve differently by country and Eq. 4 fails to hold, convergence results will depend on the PPP base-year used in the level comparison of Eq. 1, as illustrated by Sørensen (2001). 


\section{Sectoral PPP}

\subsection{Literature}

To construct sectoral PPP measures, one can use producer or consumer prices. The industry-of-origin approach aggregates unit value ratios, obtained directly from producer price surveys, to the level of aggregation of output statistics. This method was pioneered by van Ark and Pilat (1993) and is explained in detail, with recent advances, in van Ark and Timmer (2001). ${ }^{4}$ Its appeal stems from the natural concordance between price and output measures and the possibility to control for changes in product mix.

The expenditure approach provides an alternative by aggregating consumer prices using expenditure shares, obtained from consumer and retail price surveys. ${ }^{5}$ The same method is used to construct aggregate PPP. It has been the more popular approach in productivity comparisons, even though output is measured from the production side of the national accounts, while prices correspond to the expenditure side. In a comment on van Ark and Pilat (1993), Jorgenson argues:

The unit value ratios are preferable, in principle, because they represent ratios of producers' prices for the two countries being compared. [...] The practical disadvantages of unit value ratios largely outweigh their conceptual advantages, so the purchasing power parities of Kravis and his associates [...] are far more satisfactory. ("Comment" on van Ark and Pilat (1993), p. 53)

The original data, compiled by Kravis et al. (1978) for 1970, contained 153 categories, but this was expanded to 210 internationally comparable 'basic headings' by 1985 . These aggregate prices and expenditures on approximately 2500 goods and services, chosen to be representative of the entire economy. The data collection is coordinated by the International Comparison Program.

The expenditure approach is described in detail in Jorgenson and Kuroda (1990) and was first used to compare sectoral productivity between Japan and the U.S. Using the same methodology, Conrad and Jorgenson (1985) extend

\footnotetext{
${ }^{4}$ Researchers at the Groningen Growth and Development Centre have been instrumental in developing this approach. Relative productivity comparisons are available online in their data set "International Comparisons of Output and Productivity by Industry" at http://www.eco.rug.nl/GGDC/icop.html.

5 The International Comparison Program (ICP) is regularly updating the data and methodology. The program was first established in 1968 as a joint venture of the UN and the International Comparisons Unit of the University of Pennsylvania. Currently, it entails a data collection and processing collaboration between many statistical agencies, foremost the World Bank, OECD, and Eurostat. Information on the program is available online at http://www.worldbank.org/data/.
}

the results and include Germany in the comparison. Lee and Tang (2001) perform similar comparisons between Canada and the U.S. for Industry Canada. ${ }^{6}$ Pilat (1996) compares sectoral productivity levels for nine OECD countries. He uses industry-of-origin data (producer prices) where available, but supplements them with expenditure PPP data for 1985.

Another decision is to determine the level of aggregation to work at. To study convergence, there is a trade-off between the level of detail-which improves the match between output and price statistics - and a broad country coverage-few countries report statistics at a detailed level over an extended period. Hooper and Larin (1989) construct a conversion factor for manufacturing and Harrigan (1999) limits the comparison to eight narrowly defined industries in machinery and equipment. Hooper (1996) maps 101 final expenditure basic headings into five broadly defined manufacturing sectors; Pilat (1996) maps 220 basic headings into 25 sectors in the OECD's STAN database. Sørensen and Schjerning (2003) limit the industries they study to total manufacturing and two sub-sectors: machinery and equipment and food, beverages, and tobacco.

The level of detail has further importance as it will influence the extent to which Eq. 4 fails to hold. At a more disaggregate industry level there is less scope for substitution, which limits the cross-country differences in expenditure patterns and thus the difference in weights used in the construction of deflators and PPPs. Relative prices are also likely to be more similar within more narrowly defined industries.

I construct expenditure PPPs, as in Pilat (1996), but for three additional years, 1990, 1993, and 1996, and for all countries in Bernard and Jones (1996). Even though a conversion factor is only needed in a single year to study sectoral convergence, I calculate sectoral PPP for multiple years to test whether they adequately capture relative price changes. The implicit assumption that relative real growth rates are equally well measured by Eqs. 2 or 3 is questioned in another comment on van Ark and Pilat (1993) by Frank Lichtenberg:

Another, less serious limitation of the paper's approach is that the authors constructed "benchmark" estimates of relative productivity levels for

\footnotetext{
${ }^{6}$ Using sectoral PPPs in a productivity comparison using gross output, as in Jorgenson and Kuroda (1990), or adjusting unit value ratios for "double deflation", as in van Ark and Timmer (2001), requires detailed and internationally harmonized input-output tables. This is beyond the scope of this paper and I limit myself to comparing value added per worker, using sectoral PPP to convert value added directly. I similarly ignore the issue of aggregation as the merits of different methods, most notably the Geary-Khamis and EKS methods-are still debated, see for example Dowrick and Quiggin (1997) or OECD (2002).
} 
only a single year-1987; ("Comment" on van Ark and Pilat (1993), p. 58).

While studies using sector-specific conversion factors have implicitly assumed that (4) holds, I will test the relationship explicitly. ${ }^{7}$

\subsection{Data and construction}

The construction of sectoral PPPs has three components to it. First, the price information is mapped into the industrial classification of sectors. Second, prices are aggregated to the level at which output statistics are available. Third, adjustments are made for trade and indirect taxes.

Price and expenditure data on 220 basic headings for most OECD countries was obtained directly from the OECD's Statistics Department. Nominal and real value added and employment at the 2 digit ISIC Revision 3 industry classification are from the STAN database (Volume 2004, release 7). A number of judgement calls have to be made to perform the mapping from basic headings to the ISIC classification. I experimented with different criteria yielding largely similar results. ${ }^{8}$

To calculate an industry price index, prices are aggregated weighing by expenditure shares. Table 5 in the Appendix compares results with country-specific weights, producing the spatial equivalent of a Paasche index, with U.S. weights, producing a Laspeyres index, and a geometric average of the two, a bilateral Fisher index. The latter will be used in the productivity calculations even though Fisher indices are not transitive. ${ }^{9}$ As the U.S. is the productivity leader in the majority of industries, convergence results are implicitly relative to the U.S. anyway.

\footnotetext{
7 The analysis in Sørensen and Schjerning (2003) provides indirect evidence that Eq. 4 does not hold over with equality over the entire 1970-1993 period in the sectors and countries they study.

${ }^{8}$ A complete list of the mapping is available upon request. Three basic headings were omitted as they could not be matched to any specific industry: 1182022 "Other personal goods and effect", 1431011 "other products" (the very last, catch-all category), 1500000 "change in stocks". Two other basic headings had to be omitted as they capture purchases abroad: 1191011 and 1600000 . Consumption of fixed capital by hospitals, non-profit institutions, and educational institutions are included in the sector where they sell their services. Implicitly this assumes that the cost of these expenditures will be passed on to consumers in the price of their services.

9 One can also use a geometric average of the U.S. and countryspecific weights, as in Hooper and Larin (1989). Results are virtually indistinguishable. This is consistent with recent results in Rao and Timmer (2003). They investigate the sensitivity to different weighting schemes in aggregating unit value ratios and find that the main impact is at the product level, not the "branch level" (comparable to basic headings). Hill (1999) and Rao and Timmer (2003) construct transitive conversion factors.
}

The expenditure PPPs have to be adjusted for differences in indirect taxes or subsidies, following Pilat (1996), as these are excluded from the output statistics:

$P P P_{\text {net }}^{i}=P P P_{\text {expenditure }}^{i} /\left(\frac{1+\left(\frac{\text { Tax }- \text { Subsidy }}{\text { Production }}\right)_{i}}{1+\left(\frac{\text { Tax }- \text { Subsidy }}{\text { Production }}\right)_{U S}}\right)$.

Gross expenditure prices are divided by the relative net tax difference with the U.S. The observed indirect tax ratios are taken from the ISDB data set, produced by the OECD, and vary by country, industry, and year. ${ }^{10}$

Because some production is exported and some expenditure is imported, expenditure prices are adjusted for trade to mirror more closely prices fetched by domestic producers. We follow the adjustment in Hooper (1996). The observed domestic price levels $\left(P P P^{j}\right)$ are adjusted for difference with world prices $\left(P^{\text {World }}\right)$, to the extent that the country is a net exporter or net importer:

$P P P_{\text {adjusted }}^{j}=\frac{P P P^{j}+\frac{X_{j}-M_{j}}{Y_{j}}\left(P^{\text {World }}-P P P^{j}\right)}{P P P^{U S}+\frac{X_{U S}-M_{U S}}{Y_{U S}}\left(P^{\text {World }}-P P P^{U S}\right)}$,

where the world price is obtained as the weighted average of all domestic prices using each country's output share as weight. The denominator $\left(Y_{j}\right)$ is domestic production, approximated by value added multiplied by the average output/value added ratio if missing. If a country is a net exporter and its domestic price is below the world price, the adjustment will raise PPP as the domestic firms receive on balance more than the domestic consumers pay.

Ideally, adjustments should also be made for differences in retail and wholesale margins to better approximate producer prices. Unfortunately, the data is only available for the total manufacturing sector and for a limited set of countries: Hooper (1996) lists wholesale and retail margins for six countries based on data from the mid-1980s. The same study also cites evidence from U.S. input-output tables that indicates that margins vary substantially across industries. Because information is not available at a more disaggregate sectoral classification, for more than 1 year, and for the majority of countries, this adjustment is omitted.

Statistics in Table 5 in the Appendix illustrate the impact of the weighting scheme and adjustments on the PPP measures for total manufacturing in 1996. As a comparison point, the first three columns of Table 6 also list the exchange rate and aggregate (official) PPP. Relative to the differences with the other conversion factors, the impact of the different calculations is minor.

\footnotetext{
10 The ISDB data set was discontinued after 1998. When sectoral tax data was missing, the average tax rate over all non-missing years is used. If data was missing in all years, the tax ratio of the industry one level up in the aggregation is used.
} 
For most countries, aggregate PPP exceeded the exchange rate, suggesting the U.S. dollar was undervalued. Sectoral PPP statistics were even higher, indicating that manufactured goods tend to be relatively cheap in the U.S. The last columns in Table 6 show the same conversion factors expressed as an index, to gauge their change over time. The depreciation of the U.S. dollar relative to most currencies overshot the change in aggregate price levels, while the prices of manufactured goods were relatively stable on average.

\section{Direct comparison of relative price evolutions}

To illustrate the importance of constructing sectoral PPP, Figs. 3 and 4 in the Appendix demonstrate that relative prices really do evolve differentially across countries. The first figure plots the price deflator in 1996 (1985 = 100) for all 2-digit ISIC manufacturing industries for three countries. The deflators are normalized in two ways: (i) by the domestic price deflator for the entire manufacturing industry and (ii) by the equivalent ratio for the U.S. The relative price increase for machinery and equipment (relative to the price increase in manufacturing) in the Netherlands was $57 \%$ higher than the comparable price increase in the U.S. The same comparisons for Canada and Japan reveal a $39 \%$ relative price increase and $8 \%$ relative price decline. In contrast, relative price increases for paper products were $4 \%$ lower in the U.S. than in Canada, but more than $30 \%$ higher than in Japan or the Netherlands.

The second figure shows that the differential sectoral price evolutions are not confined to these three countries. While the ratio of the relative price deflator for machinery and equipment to total manufacturing was higher in all but one of 13 OECD countries than in the U.S.-most statistics are positive-the difference varies from $-8 \%$ in Japan to $104 \%$ in Belgium. The reverse is true for the paper, pulp, printing, and publishing industry, where the U.S. saw the largest price increase of all 14 countries, save for Canada. The basic metals and fabricated metal products industry is intermediate, with changes in relative prices for most countries mirroring the price evolution in the U.S.

\subsection{How well do expenditure-based sectoral PPP do?}

In light of these important differences in the relative price evolution across countries, it is important to assess how well the sectoral PPPs capture relative prices. The ICP regularly evaluates its estimates, most recently in United Nations (1999), but looks mainly at the accuracy of the collected data.

One possibility is to compare the results with those from alternative approaches. Table 1 in Van Biesebroeck (2004) compares the sectoral expenditure PPPs with the unit value ratios (UVRs) for several manufacturing industries in E.U. countries, taken from O'Mahoney and van Ark (2003). The UVR estimates are invariably lower. The latter study explains this by the likely inclusion of ancillary services in the expenditure PPPs, which tend to be more expensive in the E.U. than in the U.S.

Alternatively, Sørensen (2001) and Sørensen and Schjerning (2003) verify whether different conversion factors produce convergence results which are independent of the base year for the level comparison-a necessary condition for an appropriate conversion factor. Aggregate PPP and the sectoral PPP measures they construct for manufacturing and two sub-sectors fail this test and they conclude sectoral comparisons are impossible.

In Sect. 5, I illustrate that the sectoral PPP I calculate for manufacturing performs fine on their test, at least if the level comparison is carried out using a price level between 1985 and 1996. However, this finding does not hold for every sector.

Most researchers comparing productivity across countries, even at the sectoral level, have done so using aggregate rather than sectoral PPP. A switch to sectoral PPP is only warranted if it approximates relative price changes across countries better than the aggregate measure. We test explicitly which measure-aggregate or sectoral PPP_picks up most of the price changes relative to the U.S. The relative price change in each country-industry pair is calculated in two ways: (i) from the country-specific sectoral deflators and (ii) from the change in PPP. The closer the two measures are, the more accurately equality in Eq. 4 holds. If it does, the usual practice of calculating real output growth using domestic deflators and only comparing productivity levels across countries once is valid. $^{11}$

Even though sectoral PPP is superior in theory, data limitations introduce errors. Some errors are related to the fact that we work with prices faced by consumers, while output is deflated using measures constructed from producer prices. We make adjustments, but these are imperfect. Another source of discrepancies relates to different weights used to aggregate prices in PPPs and deflators. This problem will be more serious for more aggregate industries and will be faced by unit value ratios calculated from producer prices as well. We do not have a formal test, because it is by construction impossible for

\footnotetext{
${ }^{11}$ Recall from the discussion in Sect. 2 that availability of countryspecific price deflators does not obviate the need for sectoral PPPs. While the deflators can be used to measure relative productivity growth according to Eq. 3, convergence analysis still requires a comparison of productivity levels in 1 year according to Eq. 1 .
} 
Table 1 Correlations across countries between changes in PPP and relative prices (1985-96)

\begin{tabular}{|c|c|c|c|c|c|c|}
\hline \multirow[t]{2}{*}{ Industry } & \multicolumn{2}{|c|}{ Sectoral PPP (VA deflator) } & \multicolumn{2}{|c|}{ Aggregate PPP (VA deflator) } & \multicolumn{2}{|c|}{ Sectoral PPP ${ }^{\mathrm{a}}$ (gross output) } \\
\hline & Corr. & $=$ Sign & Corr. & $=$ Sign & Corr. & $=$ Sign \\
\hline Agriculture & 0.70 & 12 & 0.66 & 9 & 0.83 & 6 \\
\hline Mining and quarrying & 0.53 & 10 & 0.32 & 9 & 0.45 & $4^{*}$ \\
\hline Manufacturing & 0.75 & 10 & 0.66 & 8 & 0.93 & 6 \\
\hline Food, beverages, tobacco & 0.63 & 10 & 0.60 & 9 & 0.91 & 4 \\
\hline Textiles, wearing apparel, leather & 0.65 & 13 & 0.63 & 6 & 0.74 & 5 \\
\hline Wood and cork & 0.42 & 12 & 0.14 & 7 & 0.85 & $4^{*}$ \\
\hline Pulp, paper, printing, publishing & 0.54 & 9 & 0.47 & 6 & 0.81 & $5^{*}$ \\
\hline Chemical and plastic products & 0.64 & 12 & 0.53 & 10 & 0.87 & 6 \\
\hline Non-metallic minerals & 0.75 & 7 & 0.64 & 6 & 0.83 & 3 \\
\hline Basic and fabricated metals & 0.45 & 10 & 0.75 & 9 & 0.60 & $3^{*}$ \\
\hline Machinery and equipment & 0.43 & 5 & 0.53 & 6 & 0.87 & $3^{*}$ \\
\hline Transport equipment & 0.71 & 10 & 0.57 & 8 & 0.95 & 6 \\
\hline Manufacturing n.e.c. and recycling & -0.06 & 8 & 0.38 & 7 & -0.24 & $3^{*}$ \\
\hline Electricity, gas and water supply & 0.56 & 11 & 0.65 & 8 & 0.69 & 6 \\
\hline Construction & 0.37 & 6 & 0.54 & 10 & 0.83 & 6 \\
\hline Wholesale/retail trade; Rest./hotels & 0.67 & 7 & 0.79 & 9 & 0.95 & 5 \\
\hline Transport and communication & 0.42 & 8 & 0.67 & 9 & & \\
\hline Financial and business services & 0.25 & 5 & 0.96 & 10 & & \\
\hline Comm., soc., pers. services & 0.92 & 12 & 0.89 & 11 & & \\
\hline Total economy & 0.88 & 11 & 0.96 & 12 & & \\
\hline
\end{tabular}

Notes: The "corr." statistics indicate the correlation across countries between relative price changes calculated in two ways. The first way is to difference the change in sectoral deflator for each country with the change in the U.S. deflator, Eq. 8. The first four columns use value added deflators and the last two columns gross output deflators. The second way is to calculate the change in PPP, Eq. 7, using sectoral PPP in the first two and last two columns and aggregate PPP in the middle columns. The statistics in the "=sign" column indicate how many of the 13 countries have the same sign on the two different estimates for the relative price evolution

${ }^{a}$ Gross output deflators are only available for six countries (five if the statistic is starred *)

PPP indices to maintain comparability over space, while retaining time consistency. ${ }^{12}$ Rather, we check the relative performance of sectoral and aggregate PPP.

Ideally, this test should be carried out using gross output price deflators, as the expenditure-based sectoral PPPs are calculated from final good prices. We use value added price deflators for two reasons. First, fewer countries report gross output. Less than half of all country-industry pairs for which we observe real value added also report real output and the time series is shorter as well. Second, the dependent variable in the convergence analysis, which has to be converted to a common currency, is value added per worker. $^{13}$

Continuing the earlier example of Japanese PPP for sector $i$, changes in PPP (sectoral or aggregate) measure

\footnotetext{
12 Results in Hill (1999) suggest that consistency can be improved by chain linking annual changes (three-yearly changes in the current application).

13 Where we observe both deflators, the correlation for relative price changes using the two different deflators is high: 0.865 . Results with gross output deflators for a limited set of countries are in Table 1.
}

$$
\begin{aligned}
\log \frac{P P P_{i t}^{¥ / \$}}{P P P_{i t-1}^{¥ / \$}} & =\log \frac{P_{i t}^{¥} / P_{i t}^{\$}}{P_{i t-1}^{¥} / P_{i t-1}^{\$}} \\
& =\log \left(\frac{P_{i t}}{P_{i t-1}}\right)^{¥}-\log \left(\frac{P_{i t}}{P_{i t-1}}\right)^{\$} .
\end{aligned}
$$

The same measure of relative price change can be obtained from the sector-specific deflation rates from the STAN database:

$$
\begin{aligned}
& \log \frac{(\text { nom. VA } / \text { real VA })_{i t}^{J, ¥}}{(\text { nom. VA } / \text { real VA })_{i t-1}^{J, ¥}}-\log \frac{(\text { nom. VA } / \text { real VA })_{i t}^{U S, \$}}{(\text { nom. VA } / \text { real VA })_{i t-1}^{U S, \$}} \\
& \quad=\log \left(\frac{P_{i t}}{P_{i t-1}}\right)^{¥}-\log \left(\frac{P_{i t}}{P_{i t-1}}\right)^{\$} .
\end{aligned}
$$

The price changes in (7) and (8) are calculated from entirely different data sources, but they should measure the same relative price evolution. ${ }^{14}$ Even if the underlying prices were identical the measures would only be exact for

\footnotetext{
14 Average changes for both price measures are listed in the Appendix of Van Biesebroeck (2004).
} 
individual products. For industry price indices aggregation weights will differ, as discussed earlier.

The first column in Table 1 lists the correlation across countries between relative deflation rates and the change in sectoral PPP over the 1985-1996 period separately for all industries. Except for manufacturing not elsewhere classified and recycling - an industry that differs a lot by country-all correlation statistics are positive and often very high. A second statistic, in the second column, lists the number of countries out of 13 for which the sign of the relative price evolution is predicted similarly by both equations. Comparable statistics for aggregate PPP are in columns (3) and (4) and for gross output deflators in columns (5) and (6).

The evidence is mixed. For the first nine industries in Table 1, Agriculture to Non-metallic minerals, and for Transportation equipment and Community, social, and personal services the correlation is higher for sectoral than aggregate PPP and the sign equality holds for more countries using sectoral PPP. For this group of industries-11 of the 20 industries included-it clearly makes sense to use the disaggregate conversion factors. In the remaining nine industries, including the total economy entry, the correlation statistics are higher for aggregate PPP, even though only six industries have more correct sign predictions using aggregate PPP. For some industries, the use of sectoral PPP will be relatively inconsequential, but for others, most notably manufacturing, not elsewhere classified and recycling, transportation and communication, and financial and business services, using sectoral PPP would introduce noise. $^{15}$

Working at a less aggregate sectoral level improves the performance of sectoral PPP. Because information is not available for all 14 countries, results are not reported in Table 1. For example, distinguishing between the subsectors of Transportation and communication (the fourth last industry in Table 1) gives a clear advantage to sectoral PPP in predicting communications prices. The correlation advantage for sectoral PPP (relative to aggregate PPP) is $0.78(0.69)$ and 10 (seven) of the 11 signs are predicted correctly. ${ }^{16}$ Similarly, for textiles and wearing apparel (excluding leather products from the fifth industry), the correlation advantage of sectoral versus aggregate PPP amounts to 0.62 vs. 0.51 , a lot larger than for the aggregate. Only 10 countries report information for this sub-sector,

\footnotetext{
15 Similar results for shorter time changes, in Van Biesebroeck (2004), are somewhat less supportive for sectoral PPP. For short run changes, the information to noise ratio in sectoral PPP seems lower. The same paper also contains a limited set of results for unit value ratios. Here as well, the correlations tend to be higher for industries higher up in Table 1.

${ }^{16}$ For the transportation sub-sector, the two conversion factors produce similar results.
}

Table 2 Correlations across industries between changes in PPP and relative prices (1985-96)

\begin{tabular}{|c|c|c|c|c|}
\hline & \multicolumn{2}{|c|}{$\begin{array}{l}\text { All } 20 \text { sectors } \\
\text { from Table } 1\end{array}$} & \multicolumn{2}{|c|}{$\begin{array}{l}\text { First } 13 \text { sectors from } \\
\text { Table } 1 \text { (Agriculture, } \\
\text { mining, manufacturing) }\end{array}$} \\
\hline & Corr. & $=$ Sign & Corr. & $=$ Sign \\
\hline Australia & 0.22 & 13 & 0.63 & 10 \\
\hline Belgium & 0.14 & 14 & 0.27 & 9 \\
\hline Canada & -0.06 & 13 & -0.35 & 7 \\
\hline Denmark & 0.08 & 8 & -0.13 & 6 \\
\hline Finland & 0.28 & 13 & 0.50 & 13 \\
\hline France & 0.06 & 12 & 0.17 & 9 \\
\hline Germany & 0.14 & 14 & 0.10 & 9 \\
\hline Italy & 0.14 & 18 & 0.32 & 12 \\
\hline Japan & 0.06 & 19 & -0.01 & 12 \\
\hline Netherlands & 0.17 & 18 & 0.09 & 11 \\
\hline Norway & 0.14 & 14 & 0.22 & 10 \\
\hline Sweden & 0.21 & 17 & 0.18 & 11 \\
\hline U.K. & 0.21 & 15 & 0.28 & 10 \\
\hline Average & 0.14 & 14.5 & 0.18 & 9.8 \\
\hline
\end{tabular}

Notes: Relative price changes are calculated using the same two approaches as in Table 1, but now the correlations and sign equalities are calculated across industries, separately by country. All statistics use value added deflators and sectoral PPP, but the sample of industries is limited in the last two columns

but the signs on all price changes are predicted correctly with sectoral PPP, but only for four countries with aggregate PPP.

As mentioned earlier, one would expect predictions to be even more similar if gross output deflators were used instead of value added deflators. Only seven countries (including the U.S.) report this information and the comparable statistics are reported in the last two columns of Table 1. With only two exceptions (Mining and Manufacturing not elsewhere classified) the correlation statistics are higher, often a lot higher. The average correlation excluding the anomalous "not elsewhere classified" industry, is 0.81 . Clearly, changes in sectoral PPP capture an important part of relative price changes.

Another check on the accuracy of the sectoral PPPs is whether the two measures for relative price changes are correlated within each country. Aggregate PPP, by construction, ignores changes in relative prices within a country. Using aggregate PPP to compare sectoral productivity implicitly assumes that each industry experiences the same price change as the total economy or that the relative price change for each industry follows the U.S. pattern.

The correlations and sign predictions in Table 2 are for relative price changes across industries, separately by country. For 12 of the 13 countries, the change in sectoral 
PPP is positively correlated with the relative deflation rate. The average correlation statistic is 0.14 , positive but low. Only Canada has a negative correlation. Results in the third column include only the Agriculture, Mining, and Manufacturing industries in the comparison, as these industries contain the bulk of the products used to construct the sectoral PPPs. ${ }^{17}$ Several correlations increase substantially, although two more countries have negative correlation statistics. The average correlation statistic rises to 0.18 on this limited set of industries, again indicating that at least part of the relative price changes are captured. In the vast majority of cases, around $75 \%$, the direction of the relative price change predicted from sectoral PPP corresponds with the direction calculated from country-specific deflators.

\subsection{Discussion}

Before turning to convergence results, it is useful to discuss the relative importance of different concerns regarding expenditure-based sectoral PPP. Van Biesebroeck (2004) contains an explicit statistical investigation which factors are correlated with the ratio of the correlations for sectoral and aggregate PPP in the first and third columns in Table 1. Three findings stand out.

The discrepancy between consumer and producer prices is important. The adjustment for trade, for example, is imperfect: the relative success of sectoral PPP in predicting relative price changes is declining in the trade intensity of an industry. Moreover, correlations are not sensitive at all to the choice of aggregation weights for the basic heading prices, i.e., whether domestic weights or the average of domestic and U.S. weights are used. It suggests that the mismatch between expenditure and producer prices is more important than compositional changes.

A second problem is the need for a mapping from expenditure categories to industrial sectors. While the sectoral PPPs are fairly robust to the criteria used to make the mapping, the price data might not contain enough information to be representative for each industry. Service industries in particular had few products allocated to them. The ability of sectoral PPP to capture relative price changes was found to be increasing in the number of products used to construct them and was significantly reduced if only a single product could be used. ${ }^{18}$

A third situation where the use of sectoral PPP might introduce more noise than information is for industries with

\footnotetext{
17 There is a large overlap between these 13 industries and the 11 industries where the correlations and sign predictions in Table 1 favored sectoral PPP.

18 At the same time, a large standard deviation of relative prices within an industry is associated with better PPP measures. Observing prices over a wide range tends to give a more precise estimate of the average price.
}

low relative price changes. In such case, aggregate PPP will do nicely because aggregate price changes resemble the changes in the U.S. The average absolute size and standard deviation of the difference between sectoral and economy-wide deflators are both positively correlated with the relative performance of sectoral PPP in predicting relative price changes. If sectoral prices change in line with the aggregate price level, i.e., relative prices do not change, sectoral PPP does not bring much benefit. Similarly, if changes in relative prices are relatively homogeneous across countries, there is again no need for sector-specific conversion factors.

Finally, differences across countries in the extent to which improvements in product quality are controlled for is a fourth reason why changes in sectoral PPP might be imperfectly correlated with sectoral deflation rates. Statistical agencies in each country decompose nominal output changes into price and quantity changes, counting improved quality as higher quantity. Some countries account more widely for quality improvement, which are subtracted from price increases. As a result, the interpretation of sectoral deflation rates will differ by country. Sectoral PPPs do not face the same problem, because prices of the exact same goods are compared simultaneously in each country. The relative price at any point in time is well defined and easy to measure, as long as the same products are sold in both countries. As a result, changes in sectoral PPP can differ from observed relative sectoral price changes because they measure something else, i.e., the test is inappropriate.

Industries with most scope for quality change are sophisticated manufacturing and service industries. Exactly those where sectoral PPP performed worst in Table 1. The computer industry, in Machinery and equipment, provides the best example. ${ }^{19}$ The average price per computer changed little over time, while quality improved substantially. The per unit price for all characteristics that consumers value-processor speed, hard drive capacity, quality of the video output-declines constantly. To account for this quality improvement, the U.S. Bureau of Labor Statistics estimates a decrease in the real price and uses this to deflate-in this case inflate-industry output. If the adjustment procedure varies by country, the sectoral deflation rates lose comparability. ${ }^{20}$

\footnotetext{
${ }^{19}$ Wykoff (1995) studies in detail the impact of price changes on international productivity comparisons for this industry.

20 This phenomenon is especially vivid for price changes in Machinery and equipment. The U.S. deflator indicates a price decline of $28 \%$ from 1985 to 1996, while other countries record an average price increase of $19 \%$-see Fig. 4. For example, the (domestic) relative price of machinery declined by $2 \%$ in the Netherlands, while the U.S. recorded an astonishing $59 \%$ relative price decline, quality adjusted. This produces a relative price increase of machinery relative
} 


\subsection{Other periods}

As a robustness check, we perform the calculations from Table 1 for different time periods. An additional base year, 1999 , is obtained using more recent OECD data. The discontinuation of the ISDB database by the OECD makes it impossible to perform the adjustment for indirect taxes in this year, which is why we limited the comparison to the 1985-1996 period in the previous sections.

Using the price data available through ICP, it is possible to construct sectoral PPP indices for earlier years as well. ${ }^{21}$ A number of caveats apply. The set of countries in the ICP data set varies by year. Value added or gross output information in real and nominal terms is only available continuously for eight countries, which is the set of countries studied by Sørensen and Schjerning (2003) in their 'group 4,.22 Prices are available for fewer products: on average, for 150 product groups, as opposed to 220 basic headings in the OECD data. Moreover, goods that are classified into services or more differentiated manufacturing products are notably underrepresented. Almost two thirds of ICP products are manufacturers and $42 \%$ of manufacturers are in the first category: 'Food, beverages, and tobacco'. The adjustments for trade and indirect taxes can also not be performed throughout, as data availability on trade flows is more spotty and only three countries have information on indirect tax rates in the earliest years. Keeping these limitations in mind, the ICP data allows the construction of sectoral PPP for three additional base years: 1970, 1975, and 1980.

With these additional base years we again calculate the correlations between sectoral price inflation relative to the U.S. and changes in sectoral PPP, as in Table 1. These are shown in Fig. 1 for three time periods: 1970-1999 at the top, the benchmark 1985-1996 results in the middle, and 1990-1999 at the bottom. Note that the analysis is now limited to only eight countries (see footnote 22).

Four patterns stand out. First, correlations tend to be lower for shorter time horizons, especially using aggregate

\footnotetext{
Footnote 20 continued

to all goods for the Netherlands relative to the U.S. of 57\%. Evidence for this relative increase in Dutch machinery prices hardly shows in the price surveys that underlie the construction of PPP. A distinct possibility is that the U.S. goes further in making adjustment for quality improvements than other countries.

21 The data can be found online at http://pwt.econ.upenn.edu/ Downloads/benchmark/benchmark.html.

${ }^{22}$ Belgium, Germany, France, Italy, Japan, the Netherlands, United States, and United Kingdom. Note that when Sørensen and Schjerning (2003) calculate productivity convergence for 14 OECD countries, limited to the 1985-1993 period, they find that the conversion factors pass their base-year invariance test. However, over the 1970-1993 period and limited to eight countries, they do not.
}

PPP changes. This reflects that PPP holds well in the long run. Second, for long run price changes, it is rare for sectoral PPP to achieve a higher correlation, but the differences are minor. Third, the sectoral PPP measures capture recent price changes a lot better than aggregate PPP for industries to the left, i.e., primary and less sophisticated industrial sectors. Fourth, differences between the relative performance of sectoral and aggregate PPP vary substantially by industry in the bottom panel.

While the above results only rely on the information in the start and end years, we can break the time periods in smaller intervals and calculate the correlations pooling all sub-periods. The averages of these calculations over all sectors are reported in Table 3-full results are in the working paper version (Van Biesebroeck 2004). The second column contains results for the three 10-year intervals, where correlations for each industry are calculated on three times as many observations. In the fourth column, the final decade is broken into 3-year intervals.

The reduction in the absolute correlations as the time horizon shrinks shows up very clearly in the first row. Over the full 30 -year period, the average correlations is 0.89 for sectoral PPP and even higher for aggregate PPP. This falls to 0.42 for the last decade and is even further reduced for 3year price changes.

Consistent with the evidence in Sørensen and Schjerning (2003), the average ratio of the sectoral to aggregate correlation is below unity (0.96) over the 1970-1999 interval. Long run changes in sectoral PPP reflect the aggregate price evolution of a country, but fail to pick up relative price changes. The gap becomes even larger if we calculate changes by decade (second column). Limiting attention to the first nine sectors from Table 1, the pattern is slightly less negative. The average correlations for sectoral PPP are a bit higher, respectively 0.97 and 0.87 , and for a few of these sectors they are even higher than one.

Over the entire 1970-1999 period, the correlations for all manufacturing sectors are almost identical for both sets of PPPs: all ratios are in the narrow 0.95-1.04 range. Over such a long time horizon price changes vary much more by country than by sector. The advantage of incorporating sectoral price information in the conversion factors loses importance, and the noise that is introduced through these imperfect measures dominates.

In contrast, for the more recent and shorter 1990-1999 period, the average of the ratios across all industries exceeds unity, 1.07 over the entire decade and 1.06 for the 3 -year changes, making sectoral PPPs more attractive. ${ }^{23}$ This is, again, most prominently the case for the first nine sectors: the average correlation is $32 \%$ higher over the

\footnotetext{
${ }^{23}$ To calculate these averages, we omitted the top and bottom outliers; otherwise, the average ratios would be even higher.
} 
Fig. 1 Correlation between changes in prices and PPP (sectoral and aggregate). Note: The graph depicts the correlation between changes in PPP and prices across all countries by industry for 3 different time periods (the middle panel is for the benchmark results from Table 3). The correlation for sectoral PPP is expressed relative to the correlation with aggregate PPP
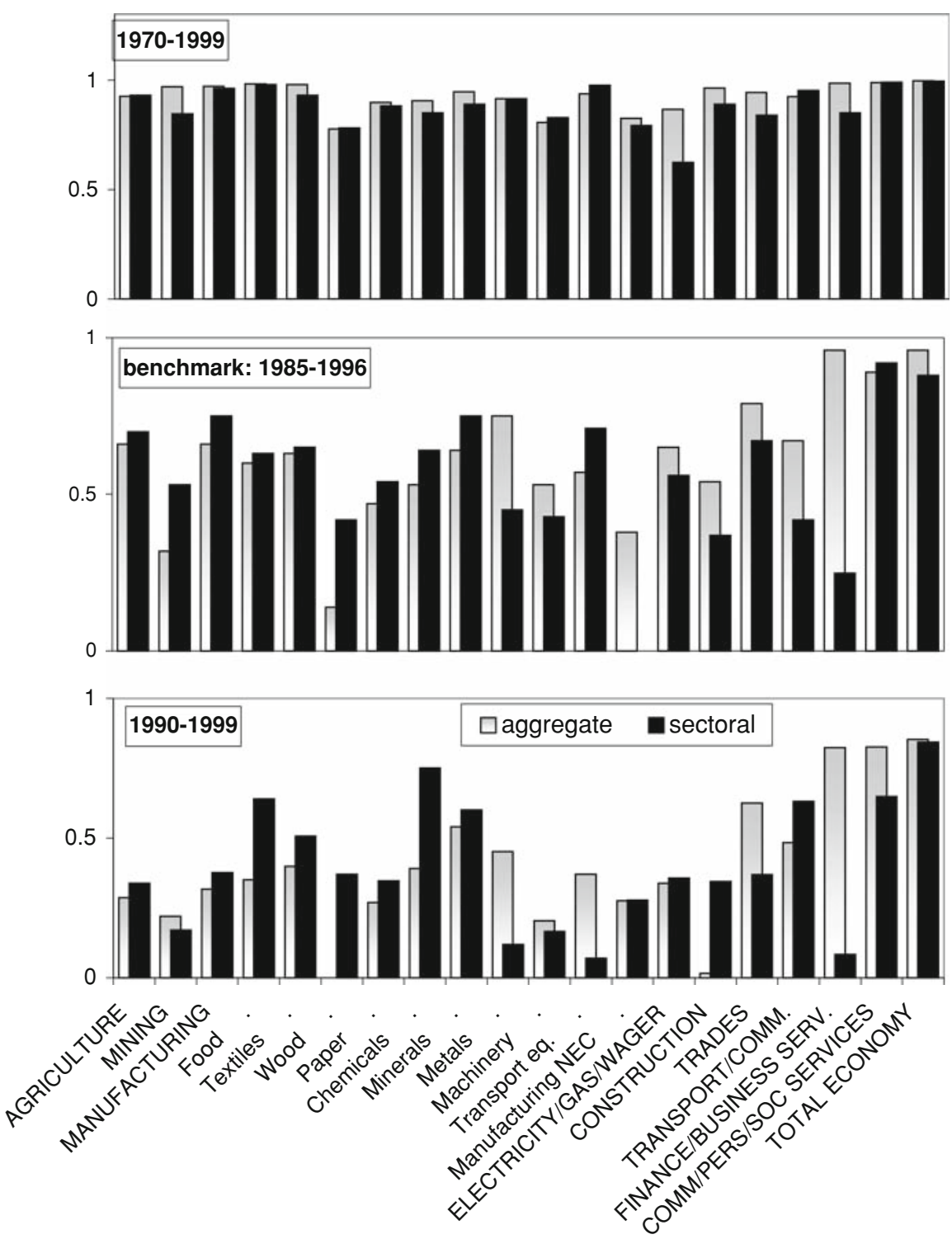

Table 3 Robustness checks for different periods

\begin{tabular}{llll}
\hline Averages across industries: & $1970-1999$ & $\begin{array}{l}1970-1980, \\
1980-1990, \\
1990-1999\end{array}$ & $\begin{array}{l}1990-1999 \\
1990-1993, \\
1993-1996, \\
1996-1999\end{array}$ \\
\hline $\begin{array}{l}\text { Correlation between relative price } \\
\text { changes and sectoral PPP changes } \\
\begin{array}{l}\text { Ratio for sectoral to aggregate PPP } \\
\quad \text { (all sectors) }\end{array}\end{array}$ & 0.89 & 0.59 & 0.42 \\
$\begin{array}{l}\text { Ratio for sectoral to aggregate PPP } \\
\quad \text { first nine sectors from Table 1) }\end{array}$ & 0.96 & 0.81 & $1.07^{\mathrm{a}}$ \\
\end{tabular}

Notes: The top line shows the average over all industries for the correlations between changes in PPP and prices (as calculated from industry deflators) across all countries, i.e. the black bars in Fig. 2. In the second and third row, the correlations for sectoral PPP are expressed relative to the correlations for aggregate PPP

a Excludes the top and bottom outliers: transportation equipment and construction

b Excludes the top and bottom outliers: textiles and wholesale and retail trade 
entire decade. Calculating the 3-year changes separately, the advantage of sectoral PPPs becomes even more pronounced: on average, the correlation is twice as high as that for aggregate PPP.

Sectoral PPPs are more likely to capture relative price changes for agriculture and less sophisticated industrial sectors and for shorter time horizons or for higher frequency price changes. Arguably, these are situations where sectoral price changes are likely to be more common. Moving from left to right in Table 3 or from right to left in Fig. 1, the similarity between relative price changes and PPP changes declines, but the relative advantage of sectoral PPP increases.

\section{Sectoral convergence}

Two types of convergence are often studied. $\beta$-convergence takes place if countries with the lowest initial productivity level experience the highest growth. We obtain the relevant coefficient by regressing average real productivity growth over the 1970-2000 period on the logarithm of the initial productivity level pooling all countries. $\sigma$-convergence takes place if the standard deviation of productivity levels across countries declines over time. We normalize the standard deviations by their value in the initial year. Clearly, $\beta$-convergence is a necessary, but not a sufficient condition for $\sigma$-convergence.

Several studies use aggregate PPP to study sectoral convergence, see for example Bernard and Jones (1996) and Wong (2006). Sørensen (2001) tests whether the results in Bernard and Jones (1996) for 14 OECD countries in six broadly defined sectors are invariant to the choice of base year for the currency conversion. He finds that in the manufacturing sector the initial productivity levels for each country relative to the U.S., and hence the convergence conclusions, are sensitive to the base year. Manufacturing sectors in different countries do seem to be converging if base years later than 1985 are used, but convergence disappears using earlier PPP measures. For the service sector, the use of aggregate PPP did not pose the same problem. Sørensen and Schjerning (2003) find the same dependency on the base year for two manufacturing sub-sectors: Food, beverages and tobacco and Machinery and equipment. Wong (2006), on the other hand, finds that his convergence results are unchanged for different base years.

The top row of Fig. 2 contains the same two graphs as in Sørensen (2001), reproduced with my data set using aggregate PPP. The bottom row shows the corresponding graphs when sectoral PPP is used for currency conversions. Relative to the previous studies, the time period is extended from 1993 to 2000 and the expenditure-based sectoral PPPs are calculated differently-they are constructed from more detailed price data and several adjustments are implemented, as explained in Sect. 3.2.

The graphs on the left plot the $\beta$-coefficient estimate with $95 \%$ confidence bounds using four base years (1985, 1990, 1993, and 1996) to carry out the currency conversion in the comparison of initial productivity levels. ${ }^{24}$ The results using aggregate PPP are insignificant for early base years, but the point estimates for the last two base years are significantly below zero, thus suggesting convergence over the 1970-2000 period. The downward slope indicates that aggregate PPP is inappropriate to carry out the productivity comparison, i.e., that Eq. 4 is violated.

Using sectoral PPP instead, in the left-bottom graph, convergence is significant at the 5\% significance level for three of the four base years and almost significant at that level for the first base year. ${ }^{25}$ Even more importantly, the line is almost perfectly horizontal, indicating the conclusions are independent of the base year. Moreover, the confidence interval is a third wider using the aggregate PPP measure, although the overlap in the intervals is clearly large.

The graphs on the right plot the standard deviation of productivity levels across countries over time to illustrate the extent of $\sigma$-convergence. Each base year for the currency conversion now generates a different line. If the conversion factors were time invariant all four lines would lie on top of one another. Even though the fit is not perfect, the lines are a lot closer in the bottom graph, using sectoral PPP, than in the top graph, using aggregate PPP. The differences only appear after a while as the standard deviations are normalized to unity in 1970 in both graphs. It is only in the 1990s that the lines diverge noticeably more if aggregate PPP is used.

Focusing on the bottom graph, the standard deviation in the sample is trending down gradually until 1994, indicative of $\sigma$-convergence early on. From 1995 onwards, the lines bend up sharply, suggesting divergence in recent years. The dispersion in manufacturing productivity between OECD countries is approximately as large in 2000 as in 1970, but in between there was a period of greater similarity. Again, we find robust convergence results using sectoral PPP, but much less so for aggregate PPP. The results also suggest that the convergence dynamics have changed over time.

Results in Table 4 illustrate the extent of convergence for all industries. For each industry, the conversion factor

\footnotetext{
${ }^{24}$ For comparability with the corresponding graphs for sectoral PPP, I limit the calculations in the top graphs to the same four base years, even though aggregate PPP is available in each year.

25 The $p$-values for the test whether the estimated coefficients differ from zero are $0.052,0.049,0.047$, and 0.050 for the four base years.
} 
Fig. 2 Two convergence tests for the manufacturing sector. Note: The graphs on the left plot four coefficient estimates with 95\% confidence bounds-one using each of the four base years - on the initial productivity level in a regression with average productivity growth over 1970-2000 as dependent variable. ( $\beta$-convergence)
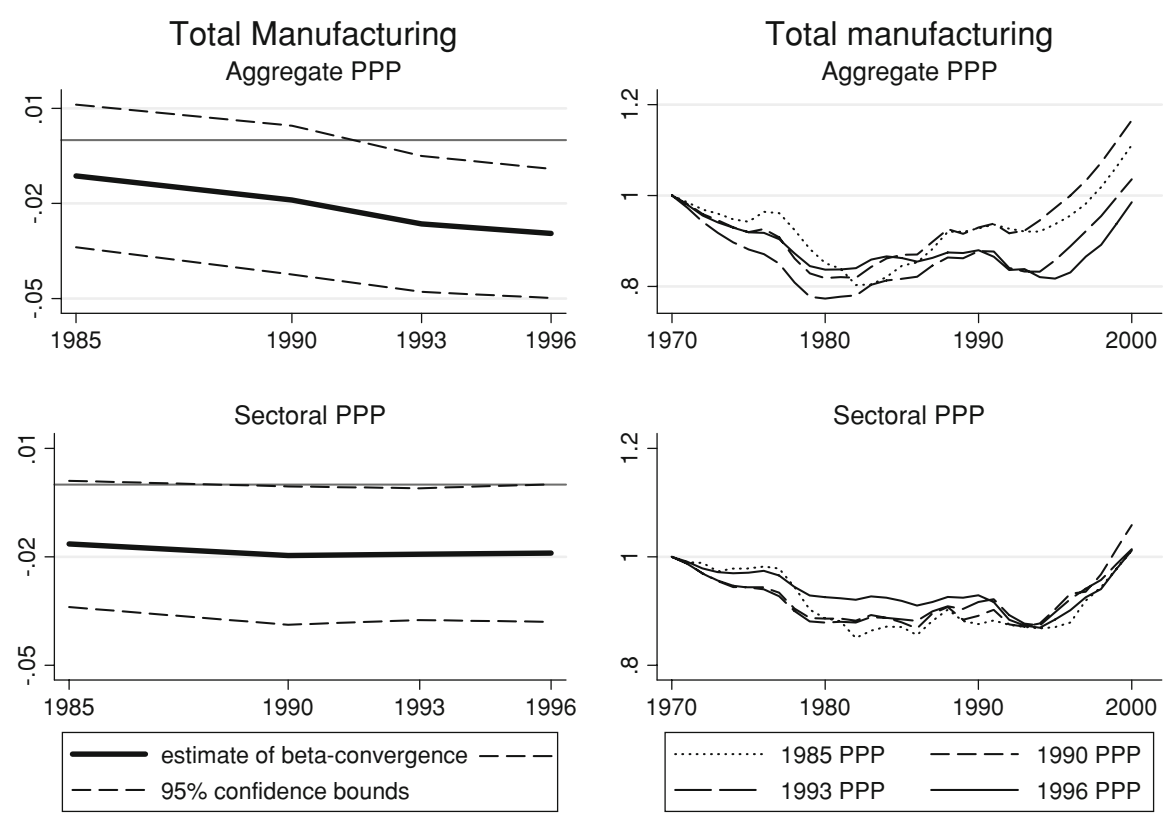

that yielded the highest correlation between relative price changes and PPP changes in Table 1 is used. The third and fourth columns show the coefficient estimate for $\beta$-convergence for the earliest and latest base years. All estimates are negative, indicating convergence is taking place. Only seven of the 40 coefficients are insignificant at the $10 \%$ level; 26 coefficients are significant at the $1 \%$ level.

The robust finding in the literature of convergence in aggregate GDP per worker is thus not solely caused by countries increasingly focusing on industries they excel in or by industries with more uniform productivity across countries rising in importance. The results clearly show that convergence is also happening at the industry level. Labor productivity levels in service sectors are converging especially rapidly. Perhaps comparative advantage plays less of a role in services or the technology for service production is easier to diffuse across countries. ${ }^{26}$ The lower $\beta$-convergence in industries producing nontradables, $-1.73 \%$ vs. $-2.38 \%$ using the average over the two base years, seems a promising area for future research. The increased importance of service sectors, the average employment share of Transport and communication, Retail and wholesale trade and hotels and restaurants, and Business and financial services jumped from 0.22 in 1970 to 0.33 in 2000, also contributes to aggregate convergence.

Results for the two base years are very similar. The correlation of the two sets of point estimates is 0.81 and also the significance levels tend to be similar across base

\footnotetext{
${ }^{26}$ Harrigan (1999) finds persistent technology differences across countries sub-sectors of the Machinery and equipment industry.
}

years. Only the average is slightly lower for the 1985 base year, at $-1.93 \%$, than for the 1996 base year, at $-2.19 \%$. This reflects the inability of sectoral PPP to capture all of the Balassa-Samuelson effects: high productivity growth and falling relative prices in manufacturing go hand in hand Sørensen and Schjerning (2003). Note however that there are only three sectors where the $\beta$ convergence conclusions are sensitive to the base year used: the two sectors included in Sørensen and Schjerning (2003), Food, beverages and tobacco and Machinery and equipment, and to a lesser extent Transport equipment.

The last two columns of Table 4 show the standard deviations across countries for labor productivity in 2000 using the two base years, normalized by the 1970 values. A value below one is evidence of $\sigma$-convergence. While some industries are converging, most notably the Total economy, Financial and business services, and some manufacturing sub-sectors, the pattern is by no means universal. For some sectors there is even clear divergence. Oil exploration in Norway, U.K., and the Netherlands is responsible for the skyrocketing standard deviations in Mining and quarrying, while the widely varying fortunes of national car companies is apparent from the Transport equipment results.

There is a tendency for industries with the highest rates of $\beta$-convergence to experience $\sigma$-convergence as well, while $\beta$-convergence estimates were insignificant for most industries showing $\sigma$-divergence. Some industries did experienced $\beta$ - but not $\sigma$-convergence. For example, in Transport and telecommunication some initial productivity laggards leapfrog the U.S. and the overall dispersion remains similar, even though low productivity countries grew more rapidly. Several of the manufacturing 
Table 4 Convergence statistics at the sectoral level for 14 OECD countries (1970-2000)

\begin{tabular}{|c|c|c|c|c|c|}
\hline \multirow[t]{2}{*}{ Industry } & \multirow[t]{2}{*}{ ISIC Rev. 3} & \multicolumn{2}{|c|}{$\beta$-convergence (OLS coefficient) } & \multicolumn{2}{|c|}{$\sigma$-convergence $\left(\mathrm{SD}_{2000} / \mathrm{SD}_{1970}\right)$} \\
\hline & & 1 & 2 & 3 & 4 \\
\hline Agriculture & $01-05$ & $-0.012 * *$ & $-0.015 * * *$ & 0.92 & 0.60 \\
\hline Mining and quarrying & $10-14$ & -0.003 & -0.008 & 9.73 & 2.72 \\
\hline Manufacturing & $15-37$ & $-0.016^{* *}$ & $-0.019 * *$ & 1.02 & 1.02 \\
\hline Food, beverages, tobacco & $15-16$ & -0.008 & $-0.018 * *$ & 1.31 & 1.03 \\
\hline Textiles, wearing apparel, leather & $17-19$ & -0.006 & -0.002 & 1.02 & 1.13 \\
\hline Wood and cork & 20 & $-0.015 * * *$ & $-0.020 * * *$ & 1.58 & 0.89 \\
\hline Pulp, paper, printing, publishing & $21-22$ & $-0.019 * *$ & $-0.027 * * *$ & 1.09 & 0.88 \\
\hline Chemical and plastic products & $23-25$ & $-0.023 * * *$ & $-0.024 * * *$ & 0.81 & 0.65 \\
\hline Non-metallic minerals & 26 & $-0.020 * * *$ & $-0.024 * * *$ & 0.79 & 0.75 \\
\hline Basic and fabricated metals & $27-28$ & $-0.029 * * *$ & $-0.030 * * *$ & 0.61 & 0.62 \\
\hline Machinery and equipment & $29-33$ & -0.021 & $-0.038 * * *$ & 1.07 & 0.66 \\
\hline Transport equipment & $34-35$ & -0.008 & $-0.011^{*}$ & 1.31 & 1.42 \\
\hline Manufacturing n.e.c. and recycling & $36-37$ & $-0.042 * * *$ & $-0.033 * * *$ & 0.19 & 0.08 \\
\hline Electricity, gas and water supply & $40-41$ & $-0.033 * * *$ & $-0.030 * * *$ & 1.11 & 0.64 \\
\hline Construction & 45 & $-0.021 * * *$ & $-0.026 * * *$ & 1.02 & 0.79 \\
\hline Wholesale/retail trade; Rest./hotels & $50-55$ & $-0.025 * * *$ & $-0.028 * * *$ & 0.95 & 0.63 \\
\hline Transport and communication & $60-64$ & $-0.019 * * *$ & $-0.023 * * *$ & 1.06 & 0.78 \\
\hline Financial and business services & $65-74$ & $-0.028 * * *$ & $-0.028 * * *$ & 0.73 & 0.58 \\
\hline Comm., soc., pers. services & $75-99$ & $-0.017 * * *$ & $-0.010 * *$ & 0.91 & 0.99 \\
\hline Total economy & 01-99 & $-0.021 * * *$ & $-0.024 * * *$ & 0.64 & 0.60 \\
\hline
\end{tabular}

Notes: $\beta$-convergence statistics are OLS coefficients on the initial productivity level in a regression with productivity growth over the 1970-2000 period as dependent variable. $\sigma$-convergence statistics are the ratios of the standard deviation (SD) of productivity levels in the final year to the standard deviation in the initial year. The statistics in columns (1) and (3) are calculated using base year 1985 for the conversion of productivity levels; in columns (2) and (4) the base year is 1996

$* * *$ Significant at the $1 \%$ level, $* * 5 \%, * 10 \%$

sub-sectors experienced convergence initially, followed by divergence towards the end of the sample period. This replicates the pattern for total manufacturing in Fig. 2. Graphs covering the entire time period for all industries are available in the working paper version (Van Biesebroeck 2004)

There are now more industries where the base year matters. The Machinery and equipment industry is again problematic, just as for $\beta$-convergence. Five more industries show $\sigma$-convergence if the 1985 base year is used, but not for the 1996 PPPs: Wood and cork, Pulp and paper, Electricity, gas, and water, Construction, and Transport and communication.

One problem is that data anomalies in a single country can have a large impact. Harrigan (1999) illustrates a number of puzzling findings that are likely to indicate data errors in the STAN database. ${ }^{27}$ In particular, deleting

\footnotetext{
${ }^{27}$ For example, the STAN database inexplicably contains employment statistics for the Netherlands in manufacturing sub-sectors pre1986 in hundreds of employees, while all other statistics are for single workers. It cannot be ruled out that there are more coding errors.
}

Belgium from the sample lowers the standard deviation using 1985 PPPs for Electricity, gas, and water and for Construction almost to the level obtained using 1996 PPPs, respectively 0.83 and 0.89 , with very little change for any of the other industries.

An additional problem for the standard deviation calculations is the country-specific weight used to construct sectoral PPP, i.e., the average of the domestic and U.S. expenditure weight, which produces nontransitive PPP indices. While adequate for $\beta$-convergence, as the U.S. is the implicit productivity benchmark in each industry, it is less appropriate to study $\sigma$-convergence. The OECD uses the EKS (Eltetö-Köves-Szulc) method to ensure overall transitivity in its published aggregate PPP statistics. ${ }^{28}$ This partly explains the greater volatility

\footnotetext{
${ }^{28}$ The EKS method uses each of the countries in the sample as a bridge to construct a PPP index between each country and the benchmark, the U.S. The geometric mean of all these indices is the final PPP estimate.
} 
in standard deviations for the manufacturing sub-sectors, which are more likely to use sectoral than aggregate PPP. For the total economy, the previous literature has not shown such conflicting conclusions for the two convergence measures partly because the U.S. remained the productivity leader throughout.

\section{Conclusions}

Relative prices evolve differently by country and one should account for this when studying sectoral convergence. We show that a non-trivial part of relative price changes are accounted for by the adjusted expenditurebased sectoral PPP indices. In 11 of the 20 industriesagriculture and mostly 'industrial' sectors-sectoral PPP approximated cross-country differences in relative price evolutions better than aggregate PPP over the benchmark 1985-1996 period. For most service industries, however, changes in aggregate PPP provide a better approximation to relative price changes. Results also indicate that the advantage of sectoral PPP over aggregate PPP increases for shorter time horizons, even though sectoral price changes can be less well approximated.

We can draw two conclusions from Fig. 2 and Table 4. First, converting total manufacturing output using sectoral PPP leads to convergence conclusions which are independent of the base year used for PPP. With a few exceptions, using the most appropriate conversion factor will achieve the same feat. Results still vary somewhat by base year-less for $\beta$ - than for $\sigma$-convergence-but this is mostly limited to a few problem industries. Sectoral PPPs perform especially poor if goods are highly differentiated, e.g., machinery and equipment, or if only a few basic heading prices are observed, e.g., financial and business services.

Second, labor productivity in total manufacturing for fourteen OECD countries has converged in the first two decades of the 1970-2000 period, but this trend has been reversed in the final decade. $\beta$-convergence conclusions are the same in every sector: initial productivity laggards enjoy higher average productivity growth. $\sigma$-convergence results are less uniform. The strong downward trend in standard deviation for the total economy or for manufacturing between 1970 and 1994 is not replicated in most industries.

Acknowledgments A previous version of the paper circulated as "Cross-country Conversion Factors for Sectoral Productivity Comparisons." I would like to thank Francette Koechlin and Scott Bradford for providing me with the OECD price data and Michael Denny, participants at the AEA meetings in San Diego and the NBER productivity meetings, and two anonymous referees for comments.

\section{Appendix}

See Appendix Tables 5 and 6.

Table 5 Sectoral PPPs for total manufacturing (1996)

\begin{tabular}{|c|c|c|c|c|c|c|}
\hline & Country weights & US Weights & Average 'Fisher' & Tax adjusted & Trade adjusted & Both adjusted \\
\hline Australia & 1.59 & 1.62 & 1.60 & 1.52 & 1.67 & 1.58 \\
\hline Belgium $^{a}$ & 1.07 & 1.08 & 1.07 & 1.09 & 1.09 & 1.11 \\
\hline Canada & 1.40 & 1.37 & 1.38 & 1.41 & 1.39 & 1.41 \\
\hline Denmark & 9.92 & 10.08 & 10.00 & 9.09 & 9.70 & 8.82 \\
\hline Finland $^{\mathrm{a}}$ & 1.30 & 1.32 & 1.31 & 1.37 & 1.30 & 1.35 \\
\hline France $^{\mathrm{a}}$ & 1.12 & 1.14 & 1.13 & 1.09 & 1.14 & 1.10 \\
\hline Germany $^{\mathrm{a}}$ & 1.07 & 1.11 & 1.09 & 1.04 & 1.11 & 1.06 \\
\hline Italy $^{\mathrm{a}}$ & 1.03 & 1.06 & 1.05 & 1.07 & 1.07 & 1.09 \\
\hline Japan & 183.0 & 183.8 & 183.4 & 173.5 & 175.9 & 166.4 \\
\hline Netherlands ${ }^{\mathrm{a}}$ & 1.02 & 1.07 & 1.04 & 1.03 & 1.06 & 1.06 \\
\hline Norway & 10.98 & 11.33 & 11.15 & 11.88 & 12.77 & 13.61 \\
\hline Sweden & 11.04 & 11.19 & 11.12 & 11.50 & 10.01 & 10.35 \\
\hline U.K. & 0.81 & 0.81 & 0.81 & 0.75 & 0.80 & 0.74 \\
\hline
\end{tabular}

Source: Own calculations

${ }^{\text {a }}$ For all countries currently in the euro zone, PPPs and exchange rate have been expressed in euros 
Table 6 Levels and changes in conversion factors for total manufacturing (1996)

Source: Exchange rates and aggregate PPP are taken from the OECD web site. Sectoral PPPs are calculated from basic heading price information, using the Fisher index formula and adjusting for indirect taxes and trade (see text for details)

${ }^{\text {a }}$ For all countries currently in the euro zone, PPPs and exchange rate have been expressed in euros

\begin{tabular}{|c|c|c|c|c|c|c|}
\hline & \multicolumn{3}{|c|}{ Levels: 1996} & \multicolumn{3}{|c|}{ Index: $1996(1985=100)$} \\
\hline & $\begin{array}{l}\text { Exchange } \\
\text { rate }\end{array}$ & $\begin{array}{l}\text { Aggregate } \\
\text { PPP }\end{array}$ & $\begin{array}{l}\text { Sectoral } \\
\text { PPP }\end{array}$ & $\begin{array}{l}\text { Exchange } \\
\text { rate }\end{array}$ & $\begin{array}{l}\text { Aggregate } \\
\text { PPP }\end{array}$ & $\begin{array}{l}\text { Sectoral } \\
\text { PPP }\end{array}$ \\
\hline Australia & 1.28 & 1.30 & 1.58 & 89 & 110 & 129 \\
\hline Belgium $^{a}$ & 0.77 & 0.91 & 1.11 & 52 & 91 & 86 \\
\hline Canada & 1.36 & 1.19 & 1.41 & 100 & 93 & 103 \\
\hline Denmark & 5.80 & 8.33 & 8.82 & 55 & 91 & 83 \\
\hline Finland $^{\mathrm{a}}$ & 0.77 & 0.99 & 1.35 & 74 & 101 & 102 \\
\hline France $^{a}$ & 0.78 & 1.00 & 1.10 & 57 & 99 & 94 \\
\hline Germany $^{\mathrm{a}}$ & 0.77 & 1.04 & 1.06 & 51 & 91 & 86 \\
\hline Italy $^{\mathrm{a}}$ & 0.80 & 0.82 & 1.09 & 81 & 130 & 126 \\
\hline Japan & 108.8 & 166.0 & 166.4 & 46 & 76 & 73 \\
\hline Netherlands ${ }^{\mathrm{a}}$ & 0.77 & 0.93 & 1.06 & 51 & 82 & 83 \\
\hline Norway & 6.45 & 9.11 & 13.61 & 75 & 95 & 101 \\
\hline Sweden & 6.71 & 9.68 & 10.35 & 78 & 121 & 109 \\
\hline U.K. & 0.64 & 0.64 & 0.74 & 82 & 117 & 126 \\
\hline
\end{tabular}

See Appendix Figs. 3 and 4

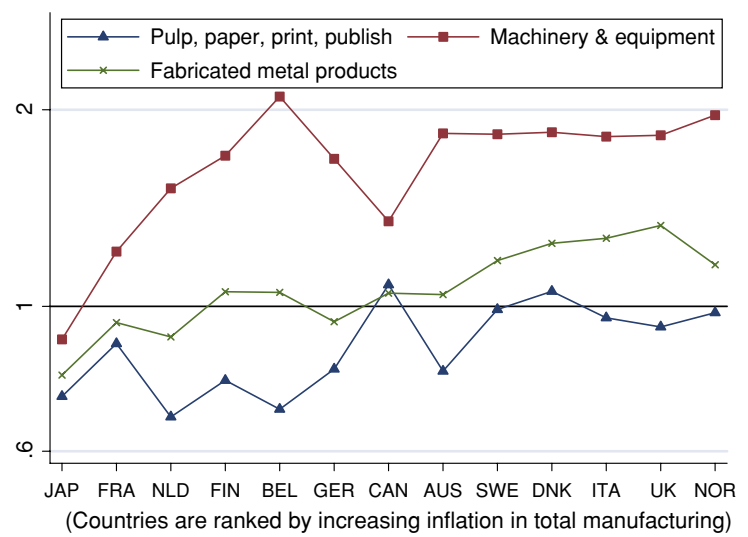

Fig. 4 Relative deflation rates for three countries across industries (1985-1996)

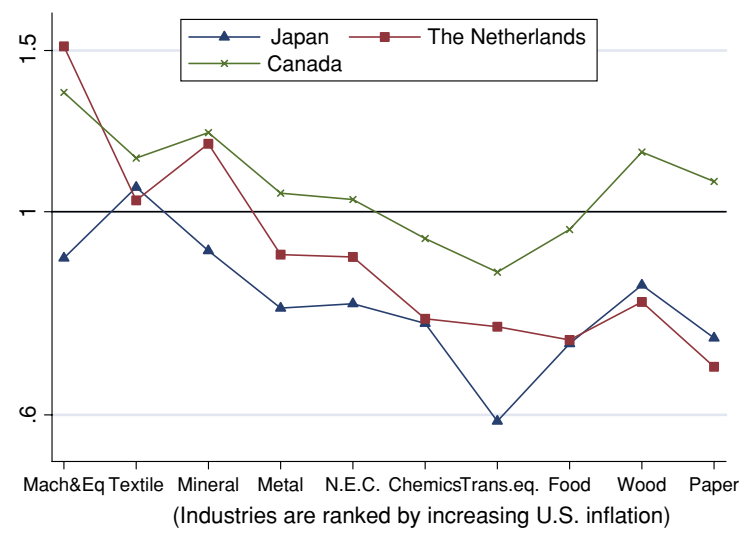

Fig. 3 Relative deflation rates for three industries across countries (1985-1996)

\section{References}

Arcelus FJ, Arocena P (2000) Convergence and productive efficiency in OECD countries: a non-parametric frontier approach. Int $\mathrm{J}$ Product Econ 66(2):105-117

Bernard AB, Jones CI (1996) Comparing apples to oranges: productivity convergence and measurement across industries and countries. Am Econ Rev 86(5):1216-1238

Bernard AB, Jones CI (2001) Comparing apples to oranges: productivity convergence and measurement across industries and countries: reply. Am Econ Rev 91(4):1168-1169

Conrad K, Jorgenson DW (1985) Sectoral productivity gaps between the United States, Japan and Germany, 1960-1979. In: Giersch $\mathrm{H}$ (ed) Probleme und perspectiven der Weltwirschaftlichen Etwicklung, Duncker and Humblot, Berlin, pp 335-347

Dollar D, Wolff EN (1988) Convergence of industry labor productivity among advanced economies 1963-1982. Rev Econ Stat 70:549-558

Dowrick S, Quiggin J (1997) True measures of GDP and convergence. Am Econ Rev 87(1):41-64

Durlauf SN, Quah DT (1999) The new empirics of economic growth. In: Taylor JB and Woodford M (eds), Handbook of Macroeconomics, vol 1A, chap 4. North-Holland, New York, pp 235-303.

Engel C, Rogers JH (1996) How wide is the border? Am Econ Rev 86(5):1112-1125

Engel C, Rogers JH (2004) European product market integration after the Euro. Econ Pol 39:347-375

Funk M, Strauss J (2003) Panel tests of stochastic convergence: TFP transmission within manufacturing industries. Econ Lett 78(3):365-371

Harrigan J (1999) Estimation of cross-country differences in industry production functions. J Int Econ 47:267-293

Hill RJ (1999) Comparing price levels across countries using minimum-spanning trees. Rev Econ Statist 81(1):135-142

Hooper P (1996) Comparing manufacturing output levels among the major industrial countries. In: Industry productivity: international comparison and measurement issues, OECD Proceedings, OECD, Paris

Hooper P, Larin KA (1989) International comparisons of labor costs in manufacturing. Revi Income Wealth 35(4):335-355 
Jorgenson DW, Kuroda M (1990) Productivity and international competitiveness in Japan and the United States 1960-1985. In: Hulten CR (ed) Productivity growth in Japan and the United States, Volume 53 of NBER studies in income and wealth, Chapter 2, University of Chicago Press, Chicago, IL, pp 29-57

Jorgenson DW, Kuroda M, Nishimizu M (1987) Japan-U.S. industrylevel productivity comparisons 1960-1979. J Japanese Int Econ $1(1): 1-30$

Kravis IB, Heston AW, Summers R (1978) World product and income: international comparisons of real growth product. Johns Hopkins University Press, Baltimore

Lee FC, Tang J (2001) Productivity levels and international competitiveness between Canada and the United States. In: Jorgenson DW and Lee FC (eds) Industry-level productivity and international competitiveness between Canada and the United States, Industry Canada Research Monograph, Ottawa, pp 155180

Malley J, Muscatelli A, Woitek U (2003) Some new international comparisons of productivity performance at the sectoral level. J Roy Statistical Society 166(1):85-104

OECD (2002) Purchasing power parities and real expenditures-1999 benchmark year. OECD, Paris

O'Mahoney M, van Ark B (2003) EU productivity and competitiveness: an industry perspective. Can Europe resume the catchingup process? Technical report, Office for Official Publications of the European Communities, Luxembourg

Pilat D (1996) Labour productivity levels in OECD countries: estimates for manufacturing and selected service sectors. Economics Department Working Papers 169, OECD, Paris
Rao DSP, Timmer MP (2003) Purchasing power parities for industry comparisons using weighted Elteto-Koves-Szule (EKS) methods. Rev Income Wealth 49(4):491-512

Rao P (2001) Integration of CPI and PPP: methodological issues, feasibility and recommendations. Joint World Bank-OECD seminar on PPPs, 30 January-2 February, Washington, DC

Sørensen A (2001) Comparing apples to oranges: productivity convergence and measurement across industries and countries: comment. Am Econ Rev 91(4):1160-67

Sørensen A, Schjerning B (2003) Is it possible to measure sectoral productivity levels? The case of manufacturing. CEBR discussion paper 2003-22

United Nations (1999) Evaluation of the international comparison programme. Technical report, United Nations, Secretary-General, Economic and Social Council

van Ark B, Pilat D (1993) Productivity levels in Germany, Japan, and the United States: Differences and causes. Brookings Pap Econ Act, Microecon 2:1-69

van Ark B, Timmer M (2001) PPPs and international productivity comparisons: bottlenecks and new directions. Working paper for joint World Bank-OECD seminar on purchasing power parities

Van Biesebroeck J (2004) Cross-country conversion factors for sectoral productivity comparisons. NBER Working Paper, No. 10279

Wong W-K (2006) OECD convergence: a sectoral decomposition exercise. Econ Lett 93:210-214

Wykoff AW (1995) The impact of computer prices on international comparisons of productivity. Econ Innovation New Tech 3(34):277-293 